\title{
EM 2020, CHEGAMOS AO v.30
}

No Editorial do n.1 de 2019 declaramos estar iniciando nossa jornada para completar 30 anos de publicação da revista, anunciando alteração na periodicidade da revista: "0 número de artigos submetidos nos estimulou a introduzir, a partir deste n.1 de 2019, a periodicidade trimestral". 1

Agora, no primeiro Editorial de 2020, damos continuidade à jornada acrescentando outra inovação no processo editorial da Informação \& Sociedade: Estudos: publicação em fluxo contínuo. Desta vez, nosso estímulo veio das novas formas de indexação dos periódicos pelo Qualis da Capes. Aliás, nesse sentido, desde o n.4 de 2019 que estamos, além do usual PDF, em ePUB e HTML.

Quando a Inf.\&Soc.: Est. iniciou sua trajetória no universo dos periódicos científicos brasileiros sua periodicidade era anual e sua publicação impressa, assim permanecendo no período de 1991 a 1997. De 1998 a 2006 a revista adotou a periodicidade semestral, publicando 16 números nesse período, quando adotou a edição exclusivamente eletrônica, sendo uma das primeiras a ser publicada no Portal de Periódicos da UFPB.

A partir de 2007 foi adotada a periodicidade quadrimestral, completando 33 números regulares e um número especial, comemorativo dos 25 anos de publicação ininterrupta, em dezembro de 2018. Nos últimos anos, o número de artigos submetidos e publicados cresceu significativamente, em especial nas seções Artigos de revisão e Relatos de pesquisa. (FREIRE; FREIRE, 2019)

Destacamos que Inf.\&Soc.: Est. está classificada como A1 no Qualis de Periódicos da Capes ainda em vigor e é um dos três periódicos brasileiros da área de Ciência da Informação indexados na base de dados Journal Citation Report ${ }^{2}$.

No biênio 2016-2017 a revista aumentou seu fator de impacto de 0,086 para 0,159, ampliando seu alcance em $75,9 \%$ dentre as revistas indexadas na base de dados Web of Science. No Google Metrics, seu índice $5 h$ é 8 e a mediana é $11 .{ }^{3} \mathrm{~A}$ revista também é indexada nas bases de dados Web of Science - Portal da CAPES, Scopus/Elsevier, Lisa, Infobila, Clase, Latindex, DOAJ e OAister (OCLC).

Para nós, Editores-científicos, que lidamos com o dia-a-dia dos processos editoriais, é uma honra contribuir para o sucesso da Inf. \& Soc.: Est., mantendo viva a ideia de seus criadores.

Gustavo Henrique Freire

Isa Maria Freire

Editores

1 FREIRE, G.H. de A.; FREIRE, I.M. Mudanças em 29 anos de publicação. Inf. \& Soc. Est., v.29, n.1, p.3-4, 2019. DOI: https://doi. org/10.22478/ufpb.1809-4783.2019v29n1.45050.

2 Listagem atualizada disponível em https://clarivate.com/blog/science-research-connect/the-2018-jcr-release-is-here/.

3 Disponível em: https://scholar.google.com/citations?hl=pt-.BR\&view_op=search_venues\&vq=Informa\%C3\%A7\%C3\%A30+\%26+Sociedade\&btnG $=$. 